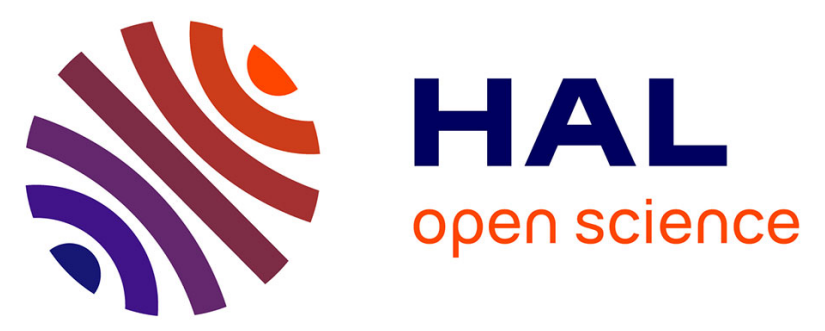

\title{
Effects of the Unified Viscoplastic Formulation and Temperature Terms on the Thermomechanical Behavior of Soldering Materials
}

\author{
Sabeur Msolli, Olivier Dalverny, Joël Alexis, Moussa Karama
}

\section{To cite this version:}

Sabeur Msolli, Olivier Dalverny, Joël Alexis, Moussa Karama. Effects of the Unified Viscoplastic Formulation and Temperature Terms on the Thermomechanical Behavior of Soldering Materials. Key Engineering Materials, 2012, vol. 498, pp. 219-226. 10.4028/www.scientific.net/KEM.498.219 . hal00782651

\section{HAL Id: hal-00782651 \\ https://hal.science/hal-00782651}

Submitted on 30 Jan 2013

HAL is a multi-disciplinary open access archive for the deposit and dissemination of scientific research documents, whether they are published or not. The documents may come from teaching and research institutions in France or abroad, or from public or private research centers.
L'archive ouverte pluridisciplinaire $\mathbf{H A L}$, est destinée au dépôt et à la diffusion de documents scientifiques de niveau recherche, publiés ou non, émanant des établissements d'enseignement et de recherche français ou étrangers, des laboratoires publics ou privés. 


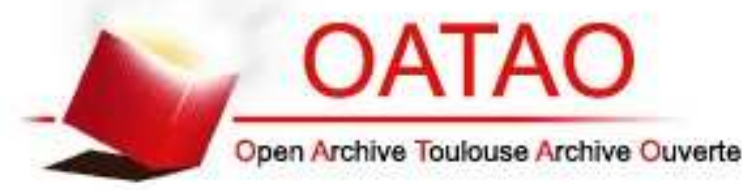

\section{Open Archive TOULOUSE Archive Ouverte (OATAO)}

OATAO is an open access repository that collects the work of Toulouse researchers and makes it freely available over the web where possible.

This is an author-deposited version published in : http://oatao.univ-toulouse.fr/ Eprints ID : 6484

To link to this article : DOI: 10.4028/www.scientific.net/KEM.498.219

URL : http://dx.doi.org/10.4028/www.scientific.net/KEM.498.219

To cite this version : Msolli, Sabeur and Dalverny, Olivier and Alexis, Joël and Karama, Moussa Effects of the Unified Viscoplastic Formulation and Temperature Terms on the Thermomechanical Behavior of Soldering Materials. (2012) Key Engineering Materials, vol. 498 . pp. 219-226. ISSN 1662-9795

Any correspondence concerning this service should be sent to the repository administrator: staff-oatao@,listes.diff.inp-toulouse.fr 


\title{
Effects of the unified viscoplastic formulation and temperature terms on the thermomechanical behavior of soldering materials
}

\author{
S. MSOLLI ${ }^{1, a}$, O. DALVERNY ${ }^{1, b}$, J. ALEXIS ${ }^{1, c}$ and M. KARAMA ${ }^{1, d}$ \\ ${ }^{1}$ Université de Toulouse ; INP/ENIT ; LGP ; 47, avenue d'Azereix ; F-65013 Tarbes, France \\ a'smsolli@enit.fr, ${ }^{b}$ Olivier.dalverny@enit.fr, 'Joel.alexis@enit.fr, ${ }^{\text {}}$ moussa@enit.fr
}

Keywords: Viscoplasticity, thermomechanical, solders, hysteresis loops, jump tests, hardening, FEM, thermal cycling.

\begin{abstract}
Solder materials are critical packaging compounds and due to usually weakest melting temperature among packaging constitutive materials, thus, they are frequently subjected to a multitude of physical phenomena: creep, fatigue and combined hardening effects. The complexity and interaction of such factors must be considered in suitable way in the mechanical behavior modeling using the appropriate material behavior laws. The choice of the mechanical model depends on several factors such as the complexity of constitutive equations to be integrated, the availability and suitability of implementation in the FE codes, the number of parameters to be identified, the capability of the model to represent the most common physical features of the material... Following these observations and in order to deal with these critical remarks, comparisons between the most common unified viscoplastic models should be done in the local and finite element levels for the decision upon the most efficient model. That is the aim of this paper with application to a tin based solder token as the test material.
\end{abstract}

\section{Thermoviscoplastic modeling of solders}

Two ways of reasoning are in general followed by researchers in the modeling efforts. In one side, available models with few material parameters are preferred because they are in generally predefined and available in the FE codes, which is leading to less identification and computation efforts but the price is a weak correlation with some material experimental data. This is acceptable in some cases based on the resemblance, the complexity of the long-term behavior of some commonly used solders, the low level of applied loadings and also the most important objective which is the lifetime prediction of the solder. We can include Anand [1] and the separated viscoplastic models [2] among these categories. On the other point of view, and inspite of the complexity of their constitutive equations, some kind of unified viscoplastic such as McDowell [3], Basaran et al. [4] Wei et al. [5] Chaboche [6] are "painfully" implemented in the FE codes by suitable integration algorithms. They also present a huge number of parameters but can describe the majority of the material physical mechanisms such creep, relaxation, Bauschinger effects, cyclic hardening, ratcheting,...These models are also suitable for complex and combined loadings such as thermal, in-phase and out-of-phase thermomechanical fatigue [7], nonproportional loadings,...they may offer the possibility of fatigue model coupling or damage model incorporation in the constitutive equations themselves leading to a realistic follow-up of the degradation of the material [8]. Based on these facts, the aim of this work is limited to the comparison of some of these models. So we present firstly a brief description of the chosen models i.e. Anand, McDowell and Chaboche unified viscoplastic models. Next, we describe the experimental tests and identification model. Then, comparisons of the numerical results issued from shear and relaxation tests are made and finally a comparison is done using finite element simulation for assembled structure. 


\section{Description of the studied laws}

The unified viscoplastic models are usually formulated using two kinds of equations: flow law which represents the inelastic strain rate variation and a set of evolution equations for describing the variation of the state variables. The flow law reflects the inelastic deformation of metals with respect to the stress and temperature levels. Then, its formulation is mainly related to the high temperature creep mechanisms such dislocation climb and dislocation glide, creep dislocation, etc [9]. The state variables could be kinematic hardening, isotropic hardening and damage of the material. In the evolution equation and in order to represent accurately the hardening/softening effects, hardening, dynamic and thermal static recovery terms are employed. Hardening represents purely the resistance to plastic deformation and it is proportional to the inelastic strain rate. Dynamic recovery terms are used for the thermally activated mechanisms which acts especially at high temperature and serves in certain manner to take into account the dislocation annihilation during deformation. Static thermal recovery terms dominate when time-dependent effects such creep and relaxation are strongly present. So, it reduces shear stresses due to dislocation interactions (hardening) and isotropically dispersed material defects.

Anand viscoplastic model. The model presents only one scalar state variable denoted by $s$ for isotropic hardening effects [10] or "deformation resistance ». The scalar form of the model is expressed as follows:

$$
\dot{\varepsilon}^{\text {in }}=A \exp \left(\frac{-Q}{R_{G} T}\right)\left[\sinh \left(B \frac{\sigma}{s}\right)\right]^{1 / m}
$$

Where $A$ and $B$ are material parameters, $Q$ is the activation energy, $m$ is the strain rate sensitivity, $R_{G}$ is the gas constant, and $T$ is the absolute temperature, respectively. A simple form of the evolution equation of $s$ is defined as

$$
\dot{s}=\left\{h_{0}\left|1-\frac{s}{s^{*}}\right|^{a} \cdot \operatorname{sign}\left(1-\frac{s}{s^{*}}\right)\right\} \dot{\mathcal{E}}^{\text {in }} ; a>1
$$

With

$$
s^{*}=\hat{s}\left[\frac{\dot{\varepsilon}^{i n}}{A} \exp \left(\frac{Q}{R_{G} T}\right)\right]^{n}
$$

Where $s^{*}$ represents a saturation value of $s . \hat{s}$ is a material parameter. The parameter $h_{0}$ is hardening/softening coefficient and $n$ is a rate sensitivity parameter for the saturation value of $s$. Finally, there was nine temperature-independent parameters to be identified which are $Q, A, n, m, a$, $h 0, \hat{s}, B$ and $s_{0}$ the initial value of the deformation resistance.

Chaboche's viscoplastic model. Contrarily to Anand's model, the Chaboche's viscoplastic model expressed here in its uniaxial form [11], includes combined hardening effects, moreover, it's includes a power term in the flow written below

$$
\dot{\varepsilon}^{i n}=\left\langle\frac{|\sigma-X|-R-k}{Z}\right\rangle^{n} \operatorname{sign}(\sigma-X)
$$

With $\langle x>=\max (x, 0), k$ is the initial yield stress and the constants $Z$ and $n$ are material parameters. Kinematic hardening is described by the internal state variable $X$ whose equation is expressed as

$$
\dot{X}=C(\operatorname{assign}(\sigma-X)-X) \dot{p}-d|X|^{r}
$$

$C, a, d$ and $r$ are material parameters and $p$ is the cumulated inelastic strain. Isotropic hardening effects are taken into account by scalar state variable $R$ which evolves according to

$$
\dot{R}=b(Q-R) \dot{p}
$$


Knowing that $R(0)=k, b$ and $Q$ are material parameters. So, in the whole model, there were nine temperature-dependent parameters to be identified in each test temperature which are $Z, n, k, C, a$, $d, r, b$ and $Q$.

McDowell's viscoplastic model. The model contains combined features as compared to Anand and Chaboche's constitutive equations. It includes activation energy term, a Zener-Hollowman parameter for creep activation mechanisms and finally combined kinematic/isotropic hardening equations as for Chaboche's model $[12,13]$. In this case, flow law is expressed in the uniaxial form as follows

$$
\dot{\varepsilon}^{i n}=A \Theta\left\langle\frac{|\sigma-X|-R-k}{Z}\right\rangle^{n} \times \exp \left(B\left\langle\frac{|\sigma-X|-R-k}{Z}\right\rangle^{n+1}\right) \operatorname{sign}(\sigma-X)
$$

With $A, n, Z$ and $B$ are material parameters.

The Arrhenius Term $\Theta$ used in the flow law is given by

$$
\begin{cases}\Theta=\exp \left(-\frac{Q}{k T}\right) \quad \text { for } T \geq \frac{T_{m}}{2} & \text { for } T \leq \frac{T_{m}}{2} \\ \Theta=\exp \left(-\frac{2 Q}{k T_{m}}\left\{\ln \left(\frac{T_{m}}{2 T}\right)+1\right\}\right) & \end{cases}
$$

$T_{m}$ is the melting temperature, $Q$ the activation energy, and k the Boltzmann's constant. In the other hand, $X$ is token as the sum of $X_{1}$ and $X_{2}$ in such a way that

$$
\dot{X}_{1}=C\left(\operatorname{assign}(\sigma-X) \dot{p}-X_{1} \dot{p}-C_{1} a \Theta X_{1}^{m_{1}}\right)
$$

And

$$
\dot{X}_{2}=H^{*}\left(\operatorname{sign}(\sigma-X) \dot{p}-C_{2} \Theta X_{2}^{m_{2}}\right)
$$

Coupling between $R$ and $b$ is considered using the variable $\omega$ so

$$
\begin{aligned}
& \dot{R}=\sqrt{\frac{3}{2}}(1-\omega) \mu^{\prime}\left((Q-\chi) \dot{p}-Q C_{\chi} \chi^{m_{\chi}} \Theta\right) \\
& \dot{a}=\omega \mu^{\prime}\left((Q-\chi) \dot{p}-Q C_{\chi} \chi^{m_{\chi}} \Theta\right)
\end{aligned}
$$

with $R(0)=k$ and $a(0)=a_{0}$.

The McDowell's model presents sixteen parameters to be determined. Only $C, H^{*}, a 0, k, \mu^{\prime}$ and $Q$ are temperature-independent parameters. It's obvious that the formulation of the constitutive equations differs from a model to another: Anand proposes an Arrhenius term to improve for thermal effects description in such a way that the model parameters are temperature-independent. But he only used one evolution equation which contains only a hardening term (proportional to the inelastic strain). For the time-dependent effects, he uses a sin hyperbolic term in conjunction with the Arrhenius Term. Chaboche introduces a power term similar to Norton creep law without introducing explicitly temperature dependent terms. Following these facts, all the model parameters are temperature dependent and must be identified in each temperature range. Moreover, he uses more than one state variable to take into account the influence of both kinematic and isotropic hardening effects. Each equation includes simultaneously hardening, dynamic recovery and static thermal recovery terms. Contrarily to Anand and Chaboche's model, McDowell considers that the dislocation motion mechanisms can be described by an exponential Zener Hollowman parameter. He also used the Arrhenius Term for the thermal effects such as for the Anand's model and adopts a Frederick-Armstrong kinematic hardening evolution equation such as that used in the chaboche's model. In this case, some model constants are fixed as temperature-independent parameters. 


\section{Models comparison in strain controlled cyclic responses}

Models are evaluated and compared using various material behavior cases, in fact, the material exhibits isotropic hardening, kinematic hardening or both. In our cases, parameters of Anand model and a two kinematic hardening Chaboche's model are identified directly from McDowell's numerical responses. Moreover, the fact that McDowell's model can reduces to Chaboche's model in isothermal loading conditions is not certainly excluding some differences in modeling capability of the two formulations.

Effect of strain rates at various temperature ranges. The following section deals with the ability of Chaboche models to reproduce McDowell's model responses to cyclic strain controlled tests at various temperature, relaxation tests and jumps tests. The used McDowell's parameters are those of 62Sn36Pb2Ag solder [14].
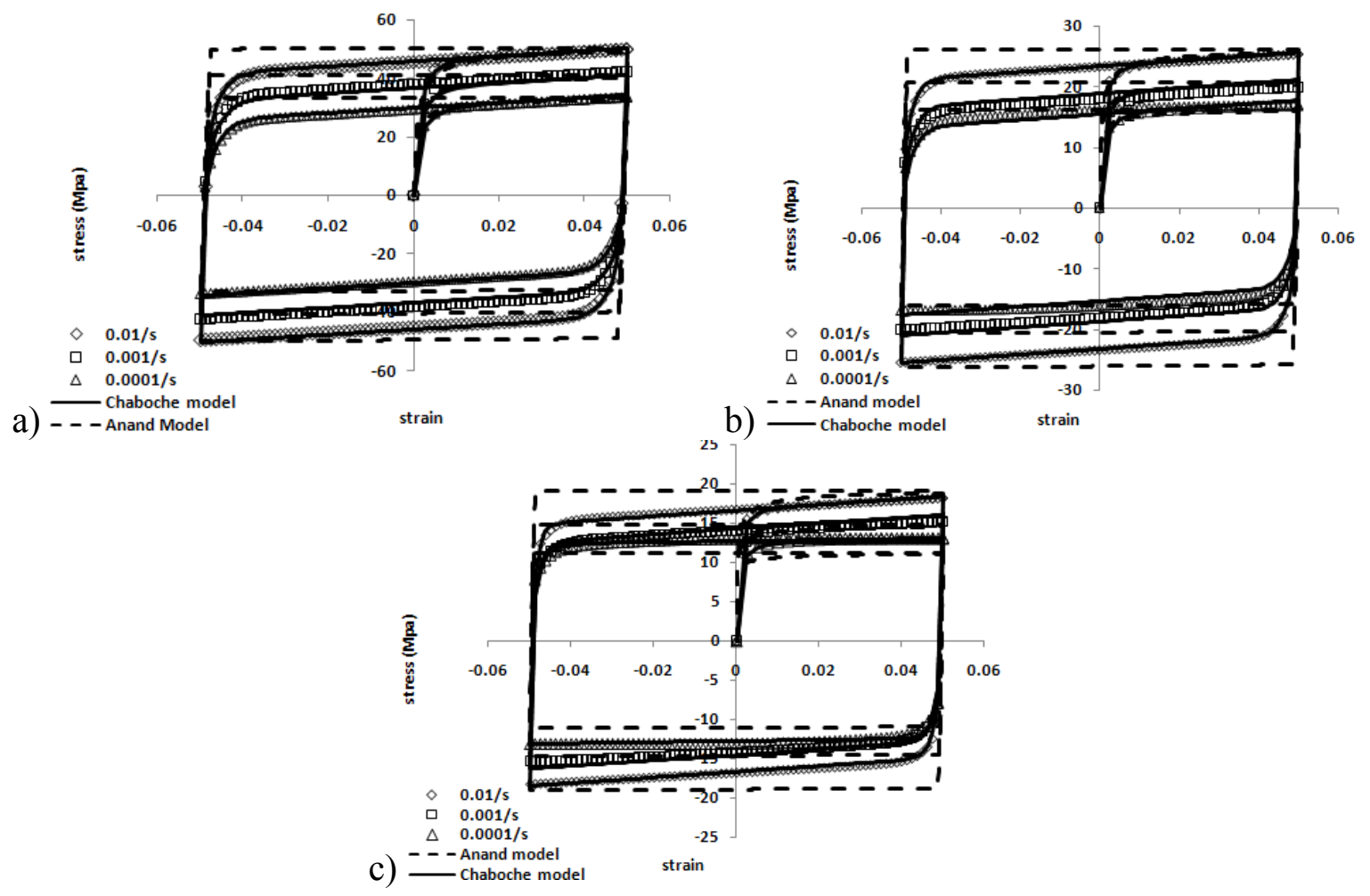

Fig. 2: cyclic strain controlled tests at various temperatures (a) $293 \mathrm{~K}$ (b) $373 \mathrm{~K}$ (c) $423 \mathrm{~K}$.

Strain controlled tests are performed at $10^{-2}, 10^{-3}$ and $10^{-4} / \mathrm{s}$ for various temperatures $293,323,373$ and $423 \mathrm{~K}$. Results shown in figure 2, indicates that Chaboche (continuous lines) and McDowell (markers) models are able to reproduce the cyclic response of the material under various strain rates and temperatures. It's also obvious that $62 \mathrm{Sn} 36 \mathrm{~Pb} 2 \mathrm{Ag}$ solder don't exhibit cyclic hardening which reduces the two models to the kinematic hardening formulation. Due to its fully isotropic Character, Anand model (broken lines) can't reproduce correctly the solder behavior with its actual formulation in comparison with McDowell numerical simulations. Moreover, effects of strain rate variation are well represented by both Chaboche and McDowell models.

Jumps tests. The aim of these tests is to evaluate the capability of the models to represent transient stages and to take into account the loading history [15]. This is important because during service, solder is continuously subjected to a variable rate of deformation due to thermal fatigue conditions. In order to examine this fact, numerical jumps tests are performed respectively at $10^{-5}, 10^{-4}, 10^{-3}$ and $10^{-2} / \mathrm{s}$. 


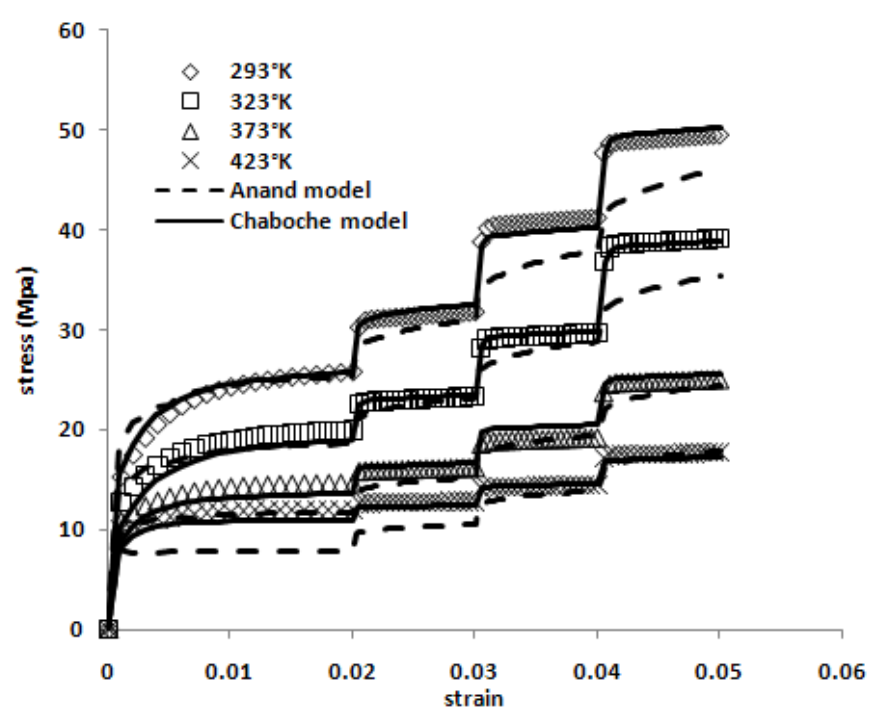

Fig. 3: Jumps tests at various temperatures.

Following figure 3, the Chaboche and McDowell models correlate well, either in high temperature level and very small strain rate as it was shown in the first tensile portion of the curves which indicates a pertinent identification procedure for material parameters too. However, in the same figure, Anand model shows in this jump test, some weakness in describing high strain rate behavior at low temperatures and vice-versa.

Stress relaxation tests. In order to evaluate the ability of the models to reproduce purely timedependent effects, stress relaxation tests are realized using an initial tensile step which is performed at $10^{-2} / \mathrm{s}$ at different temperatures followed by a $20 \mathrm{~s}$ hold time at 0.05 deformation range.

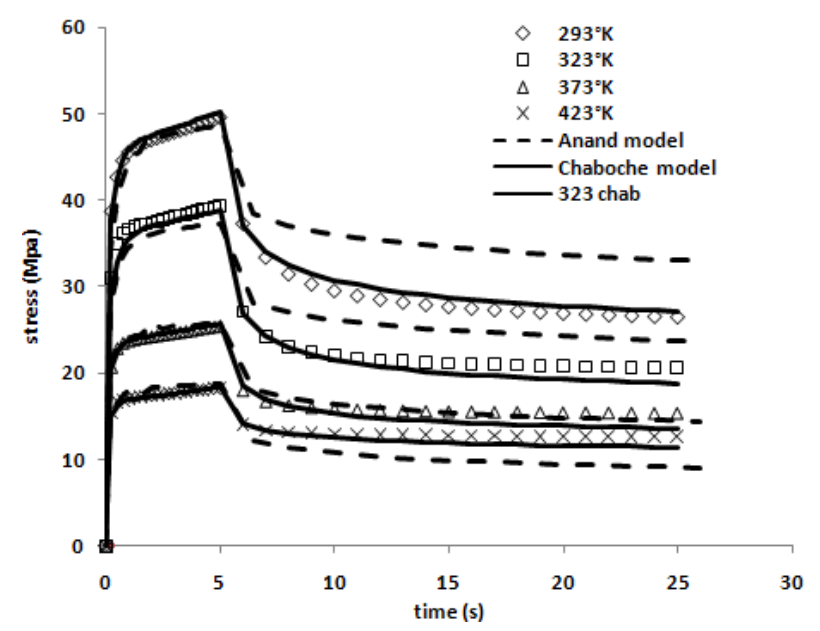

Figure 4: Stress relaxation tests at various temperatures.

Results shown in figure 4 indicate that relaxation numerical results are in good agreements for both Chaboche and McDowell laws. At high temperatures, solder reaches quickly the stress saturation level which is numerically well described. Anand model appears to be more convenient for saturation at high temperature even with regards to jump tests.

\section{Effect of thermomechanical and thermal fatigue loading}

There are two approaches which are used to represent temperature variation effects. One empirical approach is consisting on the introduction of temperature effect on the material parameters as for Chaboche's viscoplastic model. Thus, it's necessary to identify the set of material parameters of the model in each temperature range using isothermal data for different temperature levels. Then, it's 
obvious to interpolate parameters conveniently in intermediate temperatures. On the other hand, temperature effects can be used explicitly such in the Arrhenius term which means that the parameters may not be strictly temperature-dependent. Anand and McDowell's models are included in this kind of formulation. It includes also temperature rate effects for fast transient thermal regimes by introducing explicitly a rate term in the hardening equations.

\begin{tabular}{|c|c|c|c|l|c|c|c|c|}
\hline $\boldsymbol{S}_{\boldsymbol{0}}$ & $\boldsymbol{Q} / \boldsymbol{R}$ & $\boldsymbol{A}$ & $\boldsymbol{\zeta}$ & $\boldsymbol{m}$ & $\boldsymbol{h}_{\boldsymbol{0}}$ & $\hat{s}$ & $n$ & $a$ \\
\hline 39.5 & 9692.1 & 122.2 & 10.98 & 0.21 & 120554 & 30.55 & 0.0483 & 2.344 \\
\hline
\end{tabular}

Table 1: Identified Anand's model parameters for $62 \mathrm{Sn} 36 \mathrm{~Pb} 2 \mathrm{Ag}$.

According to these facts, the Anand, Chaboche and McDowell models are compared in the case of a thermomechanical and thermal fatigue loading. The parameters used for the comparison are those identified by isothermal data and shown in Table 1 and 2.

\begin{tabular}{|c|c|c|c|c|}
\hline Temp & 298 & 323 & 373 & 423 \\
\hline$E$ & 42298.4 & 39966.8 & 36080.8 & 32194.8 \\
\hline$v$ & 0.34 & - & - & - \\
\hline$k$ & 0.03 & 0.0465 & 0.08 & 0.1 \\
\hline$Z$ & 63.96 & 56.95 & 30.8 & 18.53 \\
\hline$n$ & 7.64 & 6.07 & 7.79 & 10.81 \\
\hline$C_{1}$ & 3922.88 & 3225.7 & 3378.9 & 3985.3 \\
\hline$a_{1}$ & 360.85 & 347.05 & 567.55 & 883.07 \\
\hline$d_{1}$ & $2.8 \times 10^{-5}$ & $4.72 \times 10^{-5}$ & $2 \times 10^{-5}$ & $1.4 \times 10^{-5}$ \\
\hline$r_{1}$ & 0.02 & 0.0172 & 0.02 & 0.02 \\
\hline$C_{2}$ & 85.1 & 59.31 & 38.27 & 36.34 \\
\hline$a_{2}$ & 0.01 & 0 & 0 & 0 \\
\hline$d_{2}$ & $2 \times 10^{-6}$ & $1.88 \times 10^{-6}$ & 0 & 0.00291 \\
\hline$r_{2}$ & 0.02 & 0.0173 & 0.04 & 0.01 \\
\hline$F V A L$ & 21.1 & 13.39 & 16.18 & 10.83 \\
\hline
\end{tabular}

Table 2: Identified Chaboche's model parameters for $62 \mathrm{Sn} 36 \mathrm{~Pb} 2 \mathrm{Ag}$.

Effect of thermomechanical fatigue loading. For the thermomechanical case, in-phase and out-of phase tests are performed at a strain rate of $10^{-2} / \mathrm{s}$ and a temperature between $20^{\circ} \mathrm{C}$ and $150^{\circ} \mathrm{C}$. Inphase and out-of-phase responses are shown in figure 5 for all models. It's indicating a slight difference between Anand model and both McDowell and Chaboche models. However, curves profile is still the same and there was comparable hardening behavior for all models.

a)

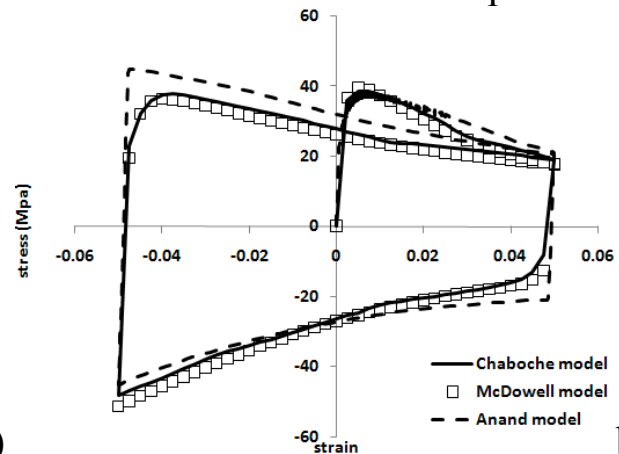

b)

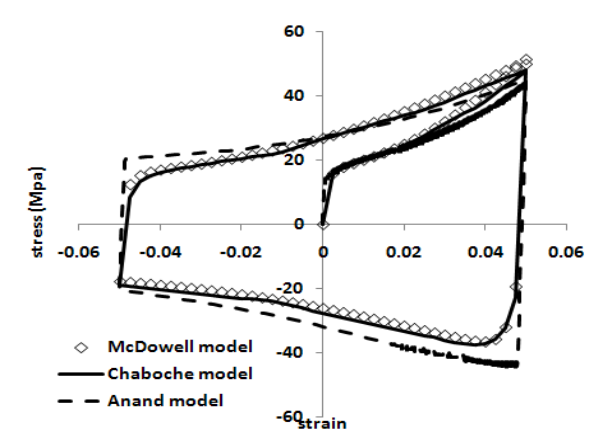

Fig. 5: (a) in-phase (b) out-of-phase TMF test.

This observation means mainly that linear interpolation of the Chaboche parameters in one hand and explicit-empirical formulation of McDowell model induce quite similar results. For the Anand model, the evolution of stress is only driven by the variation of saturation level contrarily to 
McDowell and Chaboche model where kinematic hardening contributes to the progressive dynamic recovery of the material and thus smooth profiles were obtained.

Effect of thermal fatigue loading. For the thermal fatigue effects, the comparison is made in the finite element level by simulating a thermal cycling of a 2D typical assembly of electronic components. The assembly is constituted by a soldered silicon Chip brazed to a DBC substrate by a $62 \mathrm{Sn} 36 \mathrm{~Pb} 2 \mathrm{Ag}$ solder alloy. The power assembly is presented in figure 6 .

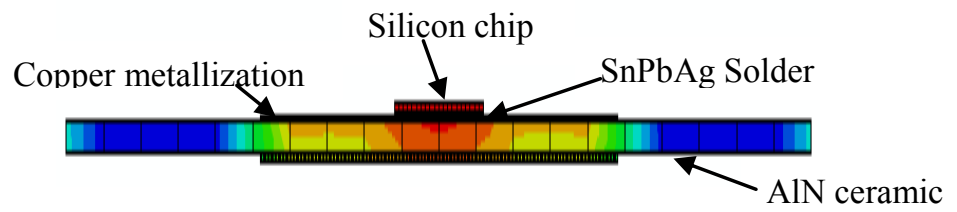

Fig. 6: Power electronic assembly.

The assembly is subjected to thermal heating-cooling cycles in air. Thermal fatigue conditions are applied to observe temperature and temperature rate influences on the studied assembly. Temperature histories are shown on figure 7. Results are compared at the more solicited regions in the solder in term of shear stress evolution.

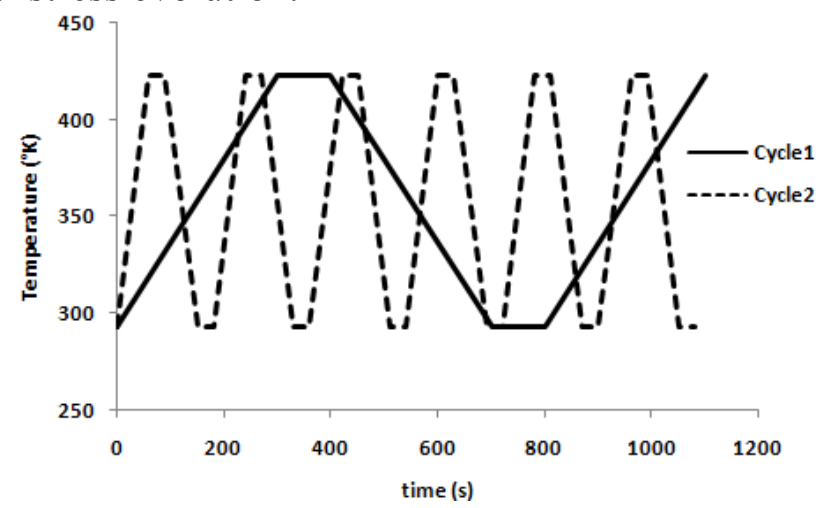

Fig. 7: Temperature histories with fast and slow transient regimes.

Results in figure 8 indicate that shear stress history prediction differs for all the models and this observation is also valuable for all the imposed thermal cycles. Anand model responses show more accumulation of plastic deformation. This is due to the independent-temperature nature of the parameters so hardening behavior don't vary so much from high to low or low to high temperature. Moreover, Chaboche and McDowell models give similar results when cycle 2 is imposed. However, diminishing temperature rate in cycle 1 , leads to divergent results. In fact, creep mechanisms (terms) are more influent in this case of loading and that's why the differences between Arrhenius term in McDowell model and Norton power law formulation in Chaboche model is more apparent.
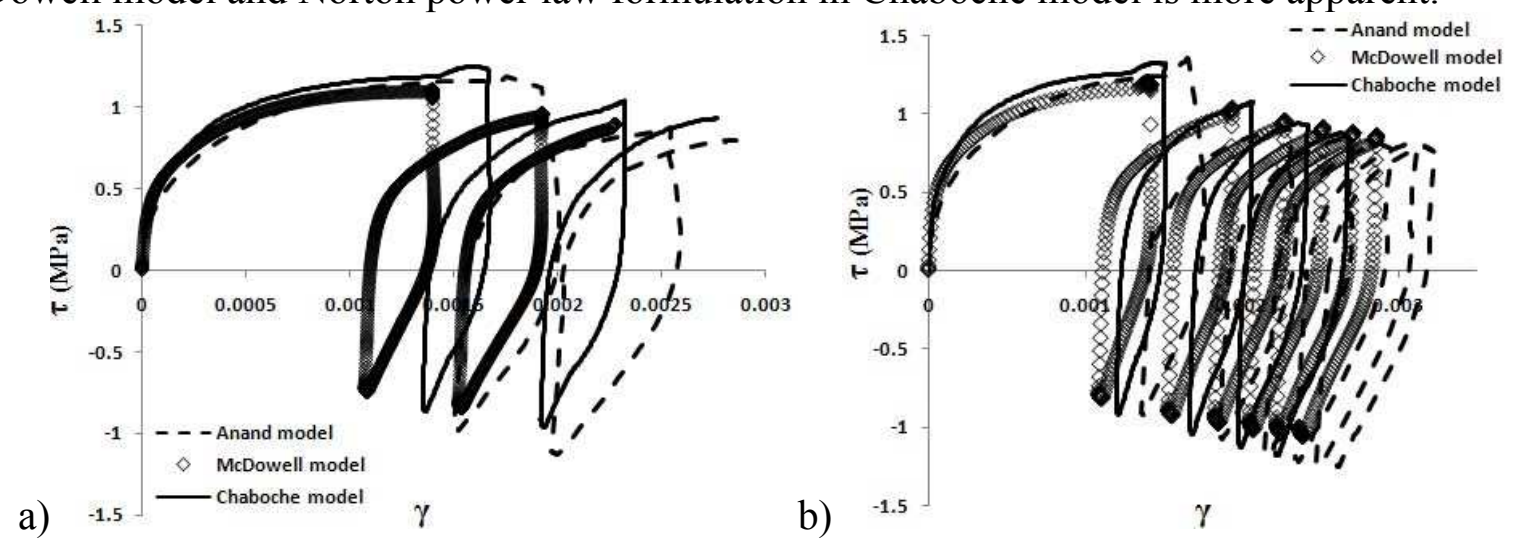

Fig. 8: Thermal fatigue responses for all models (a) Cycle 1 (b) Cycle 2.

The consequences may be observed when lifetime prediction is proceeded using based inelastic deformation energy or plastic deformation fatigue models which must be verified. 


\section{Discussions}

Following the calculated numerical responses, Anand model in its presented fully isotropic formulation is unable to describe exactly $\mathrm{SnPbAg}$ solder results obtained by McDowell model especially in the case of thermal fatigue loading. On the other hand, Chaboche and McDowell models show good agreements even when varying the imposed strain rate and temperature. Timedependent effects are also well fitted. According to the thermomechanical and thermal fatigue data, the two models show some similarities which are due to the way of taking into account temperature and temperature effects and multiple sets of identified parameters at close temperatures. Introducing a temperature rate term in the kinematic hardening equations and an Arrhenius term in the flow law in the McDowell model has incidence in the thermal fatigue tests. In fact, when temperature rates are not important, the acting creep terms in the flow laws varies differently. So, in the modeling steps and especially at fast and low thermal fatigue cycles, care must be taken for the choice of the constitutive model.

\section{Summary}

Three unified viscoplastic models are integrated and implemented in the finite element code Abaqus. The responses of these models are compared for various loading cases including isothermal mechanical tests, thermomechanical fatigue and thermal fatigue tests. Generally, no remarkable differences are present and responses profile keep resemblance excepting the case of thermal fatigue. Thus and at long term behavior, models are expected to exhibit divergence especially when they'll be used for the lifetime prediction of the solder in spite of the dependence on the coupled fatigue or damage model. These facts have to be verified with a comparative study of extensive lifetime numerical data.

\section{References}

[1] Z.N. Cheng, G.Z. Wang, L. Chen, J. Wilde, K. Becker, Soldering \& Surface Mount Technology, Vol 12, No.2 (2000), pp. 31-36.

[2] G. Z. Wang, Z. N. Cheng, K. Becker, J. Wilde, Journal of Electronic Packaging, Vol. 123 (2001), pp. 247-253.

[3] McDowell, D.L. International Journal of Plasticity, Vol. 8, (1992), pp. 695-728.

[4] Gomez, J., Basaran, C., Mechanics of Materials Vol. 38, (2006), pp. 585-598.

[5] A.H. Zhao, C.L. Chow, Finite Elements in Analysis and Design Vol.43 (2007), pp. 681-690.

[6] P. Chellapandi, R. S. Alwar, Int. J. Num. Meth. Eng. Vol. 43, (1998), pp. 621-654.

[7] Yi-Shao Lai, T. H. Wang, Microelectronics Reliability, Vol. 45 (2005), pp. 575-582.

[8] J.Gomez, C. Basaran, Int. J. Solids and Structures, Vol. 43 (2006), pp. 1505-1527.

[9] Stouffer, D.C. and Dame L.T. : Inelastic Deformation Of Metals: Models, Mechanical properties and metallurgy, (New York 1996).

[10] L., Anand, J. Plasticity, Vol. 1, (1985) pp. 213-231.

[11] S. Wippler, M. Kuna, Engineering Fracture Mechanics, Vol. 75 (2008) pp. 3534-3544.

[12] Ning Bai, Xu Chen, Int. J. Plasticity, Vol 25. No.11. (2009), pp. 2181-2203.

[13] J. C. Moosbrugger, D. L. McDowell, J.Mech. Phys. Solids,Vol. 38. No.5. (1990), pp. 627-656.

[14] Fu, C., McDowell, D.L. and Ume, I.C, J. Electron. Packag, Vol 120, (1998), pp. 24-34.

[15] Krausz, A. S., Krausz, K., Unified constitutive laws of plastic deformation. (California 1996). 